\title{
Menéndez y Pelayo y Roa Bárcena: una disensión académica
}

\author{
Datos para una biografía de Roa Bárcena
}

ROA BARCENA, ACADEMICO

M aximiliano, el iluso emperador de México, "considerando que el cultivo de las ciencias y de las bellas letras requiere protección y estímulos, y que sus adelantos figuran entre los más esenciales elementos del engrandecimiento y renombre de las naciones; queriendo distinguir y recompensar a los que se hacen notables en una y otra carrera", ${ }^{1}$ decretó el establecimiento de una Academia Imperial de Ciencias y Literatura en la capital de su imperio el 10 de abril de 1865. El intento de esta academia y su objeto principal eran impulsar el progreso y adelanto de las ciencias y la literatura, dando así un centro al movimiento científico y literario del imperio $\mathrm{y}$ creando un punto de reunión para "las personas que se hayan distinguido por sus trabajos científicos y literarios." 2 Tres fueron las clases que se establecieron para esta academia, a saber: la matemático-física, la filosófico-histórica y la filológico-literaria. En otra ocasión nos ocuparemos de dar más detalles acerca de. esta academia, limitándonos por ahora a mencionar que entre los académicos famosos figuraban José Fernando Ramírez, García Icazbalceta, Orozco y Berra, Pimentel, así como también José María Roạ Bárcena, que por entonces se ocupaba de la redacción del periódico La Sociedad. Don José María Roa Bárcena (1827-1908), natural de Jalapa, Veracruz, había de llegar a distinguirse en la literatura mexicana como cuentista, como poeta, como crítico, como periodista, como 
historiador y como traductor. Figura desde esta época Roa Bárcena entre los literatos del México del siglo xix, y ya para 1875, al fungir como tesorero de la recién creada Academia Correspondiente de la Real Española, había publicado Flores de mayo o mes de María en 1856, Poesías líricas en 1859, Ensayo de una historia anecdótica de México en los tiempos anteriores a la conquista española en 1862, Leyendas mexicanas, cuentos y baladas del norte de Europa, y algunos otros ensayos poéticos en el mismo año de 1862, Novelas originales y traducidas en 1870 y Nuervas poesías en 1875, amén de toda una serie de artículos periodísticos y literarios que se publicaron en los principales periódicos y revistas del México de aquellos tiempos.

Ya en junta de 24 de noviembre de 1870, la Real Academia Española había propuesto la creación de Academias Correspondientes Americanas, con el objeto de "reanudar los violentamente rotos vínculos de la fraternidad entre americanos y españoles; restablecer la mancomunidad de gloria y de intereses literarios, que nunca hubiera dejado de existir entre nosotros; y por fin, oponer un dique, más poderoso tal vez que las bayonetas mismas, al espíritu invasor de la raza anglosajona en el mundo por Colón descubierto." ${ }^{3}$ Cinco años más tarde, el 13 de abril de 1875, la Academia Mexicana Correspondiente de la Española celebró su sesión preliminar. ${ }^{4}$ Sus miembros fundadores fueron Lerdo de Tejada, Ormaechea, Bassoco, Cardoso, García Icazbalceta, Moreno y Jove, Segura y Ramírez, de los cuales Moreno y Jove y Ramírez murieron antes de tomar su lugar entre los otros. Después de reunirse estos socios fundadores para aprobar la formación de la Academia, la Real Española la reconoció por carta de Tamayo y Baus de junio 27 de 1875.5 Tomando sus datos de la historia entonces manuscrita de la Academia de Carreño, Annita Ker dice que "at the first regular session of the Mexican Academy, held September 11, 1875, new members, chosen in Mexico, were admitted, and José María Bassoco was elected Director, Alejandro Arango y Escandón Librarian, Manuel Peredo Censor, J. M. Roa Bárcena Treasurer, and J. García Icazbalceta Secretary." " En cambio, el mismo Carreño, al publicar esa historia de la Academia Mexicana en 1945 que consultara Annita Ker en 1931, nos dice que Roa Bárcena fué el primero en ocupar la silla académica número 10 desde el 25 de septiembre de 1875 hasta el 21 
de septiembre de 1908, fecha de su muerte. ${ }^{7}$ Esta discrepancia que existe entre el 11 y el 25 de septiembre se deberá sin duda a la confusión en que se encontraban los papeles de la Academia cuando Carreño, hoy secretario de ella, trató de consultarlos y arreglarlos al escribir su historia en 1925. Sea de ello lo que fuere, el caso es que Roa Bárcena ya ocupaba un puesto académico para septiembre de 1875 .

Fué Arango y Escandón quien sugirió, en 1876, que la Academia publicase unas Memorias que aún subsisten, aunque, como dice Annita Ker, "are published as often as it is convenient to put into print the material that has accumulated, material which consists of studies on philology, data for literary history, and translations from the Greek and Latin." 8 Entrégase con afán Roa a su nueva tarea académica: así vemos que en el primer tomo de las Memorias aparecen sus Datos y apuntamientos para la biografia de D. Manuel Eduardo de Gorostiza;" en el segundo tomo su "Alocución en la solemnidad fúnebre celebrada por el Casino Español el 4 de marzo de 1879 en honor del señor don Anselmo de la Portilla"; ${ }^{10}$ en el tercero la "Aparición de Creusa", traducida de Virgilio, ${ }^{11}$ y la "Conferencia acerca de don Manuel Carpio - En la Sociedad Literaria "Sánchez Oropesa", de Orizaba"; ${ }^{12}$ en el cuarto tomo el "Suplicio de Laoconte", tomado de la Eneida de Virgilio ${ }^{13}$ y el artículo "Antología de poetas de México", del cual hablaremos más tarde; ${ }^{14}$ y en el sexto volumen se publican su "Carta sobre los "Ripios aristocráticos y académicos' de don Antonio de Balbuena", 1.5 y "I.os padres de la muerta" (dedicada a Casimiro del Collado con motivo de la muerte de su hija Margarita, acaecida en Francia) ${ }^{16}$ así como también aparece en este sexto tomo el artículo de Manuel G. Revilla en que se hace el retrato académico y literario de Roa Bárcena a su muerte en el año de 1908. ${ }^{17}$

Al principio, parece que, según Icazbalceta, la Açademia celebraba dos juntas cada mes, en los días 2 y 16 ; después acordó que fueran tres, en los días 2, 12 y 22, y más tarde "espera que pronto podrán verificarse semanariamente." 18 Parece, sin embargo, que a pesar de que la Academia era entonces mucho más activa de lo que había de ser después, estas reuniones semanarias no llegaron a tener lugar. 
El 4 de agosto de 1878 encontramos a Roa entre los académicos que presidieron la ceremonia que su corporación celebró en honor de Alarcón y otros ingenios mexicanos en la iglesia de La Profesa, teniendo a su cargo la oración fúnebre el obispo de Tamaulipas y biógrafo y amigo de Roa Bárcena, Ignacio Montes de Oca, el famoso Ipandro Acaico. ${ }^{19}$

Ya en 1877 había muerto el conde de Bassoco, siendo nombrado Alejandro Arango y Escandón director interino primero y permanente más tarde, cargo que desempeñaría hasta su muerte en 1883. Con motivo de esta elección, vemos una de las salidas ingeniosas de Roa Bárcena. Al tratar de elegir director propietario de la Academia, ya que Arango lo era únicamente interino como ya dijimos, el mismo don Alejandro trató de apoyar la candidatura del obispo Montes de Oca, a pesar de las protestas de dicho obispo. A todos los argumentos de Montes de Oca se le respondía victoriosamente, hasta que Roa Bárcena resolvió la cuestión con esta observación: "¿Queréis, por ventura, poner mitra a la Academia ?" 20

Por encargo de la Academia, pronuncia Roa el 4 de marzo de 1879 su ya mencionada alocución en la solemnidad fúnebre celebrada por el Casino Español en honra del distinguido periodista y escritor español Anselmo de la Portilla, que tanto hiciera por estrechar las relaciones con la Madre Patria.

En la sesión de septiembre 23 de 1879, Roa Bárcena y Manuel Peredo resultaron reelectos para los cargos de tesorero y censor, respectivamente, cargos que aún desempeñaban a satisfacción de la Academia el 15 de abril de 1880, en que García Icazbalceta firmó la reseña histórica que publicara en el tomo ir de las Memorias de dicha Academia.

Ya José de Teresa, el amigo y protector de Roa, había muerto y don José María había quedado al frente de la casa de "Viuda de José de Teresa e Hijas", dando "pruebas de ser tan hábil para los negocios mercantiles, como lo había sido en el periodismo y en la bella literatura." ${ }^{21} \mathrm{Su}$ moderación, que era la norma de todos sus actos, le permitió hacer fáciles y seguras transacciones, prosperando de tal suerte los negocios de la casa Teresa que, al entregar el negocio a otras manos, había triplicado el capital. Montes de Oca dice que Roa Bárcena "tenía su despacho en los bajos de la casa que dirigía, y a ciertas horas semejaba una academia literaria más bien 
que un centro mercantil. Era el pünto de reunión de todos los literatos que moraban en la capital y de todos los que de vez en cuando la visitábamos." 22

En aquellos tiempos las bellas letras parecían contar con varias sociedades literarias, pues "actualmente no sólo existe, en la capital de la República, el Liceo Hidalgo, restablecido, hace poco, por don Ignacio Altamirano, sino la Academia Nacional de Ciencias y Literatura que sucedió, en tiempo del presidente Juárez, a la que se creó con el mismo nombre durante el gobierno de Maximiliano; la Academia correspondiente de la de la lengua de Madrid; las sociedades llamadas Porvenir, Concordia, Alianza, Netzahualcóyotl, Escudero y otras." 23 Poco, sin embargo, era lo que podian hacer estas organizaciones, y principalmente la Academia de la Lengua, en bien de la literatura y lengua nacionales, porque a esta corporación le faltaban los fondos indispensables y a sus individuos "el tiempo que reclaman estudios largos y profundos. Los que la forman no viven exclusivamente para las letras: unos dedican atención preferente a sus ocupaciones profesionales; otros a la dirección de negocios propios o ajenos; otros, finalmente, al desempeño de los cargos más elevados del Estado o de la Iglesia." 24 A pesar de estas dificultades, la Academia siguió su obra, remitiendo el mes de agosto de 1884 "la décimonona y última lista de artículos para el Diccionario" de la Real Academia Española, que se publicó ese mismo año de 1884 en su duodécima edición. ${ }^{25}$

El interés de Roa Bárcena por la Academia no llegó a decaer, y, a pesar de su edad y sus ocupaciones, era uno de los más asiduos concurrentes a sus reuniones. Juan Zamora y Figueroa en sus Ripios mexicanos o proceso contra los malos versos, de 1892, hace una curiosa referencia a la Academia: "El académico en turno es don José María Roa Bárcena, persona muy estimable y malísimo poeta; cualidades que no son incompatibles, y ojalá lo fueran, porque así vapulearía más a mi gusto a los versistas. Figúreńse ustedes que este buen señor, un día de academia, a eso de las once y media, cierra los libros Mayor y Diario de la casa De Teresa, toma con cuidado su papel borroneado, se cala el sombrero y muy echao pa elante sale con la levita desabrochada, las manos por detrás, salva sea la parte; ora mira al cielo, ora a la tierra, y oscilando a diestro y siniestro se dirige a la Biblioteca Nacional donde le espera el 
maestro Vigil, el Landlord, el académico hospitalario, que da albergue a la Academia correspondiente de y a la Española. Llegó un poco tarde, y su presencia, sombrero y papel en mano, causó sensación. García Icazbalceta le ve con su habitual franqueza; don Rafael Angel de la Peña asegura que le esperaba con ansia porque deseaba aplaudir la magnífica composición; Justo Sierra propone, que si ésta es sobre asunto histórico e indígena se espere a Chaverito; el doctor Peredo pregunta si es drama; y el señor canónigo Pagaza, que ese sí es poeta, se resigna, más por urbanidad, que por otra cosa, a escuchar una poesía que de seguro le va a romper los oídos. Vigil espera con calma.", 26

E1 polígrafo García Icazbalceta fallece el 26 de noviembre de 1894 y la mañana del 28 en la iglesia de San Cosme, encontramos a Roa Bárcena, junto con Casimiro del Collado, Vigil, Peña y Sosa, representando a la Academia en el sepelio del difunto director de esta corporación. ${ }^{27}$ En la junta de la Academia habida el 10 de diciembre del mismo año del 94, quedó resuelto que se celebraría una sesión pública con la mayor solemnidad posible en honor de su difunto director. Para formar el programa respectivo fueron nombrados Roa Bárcena, Gutiérrez y Otero y Rafael Angel de la Peña. ${ }^{28} \mathrm{E} 1$ sábado 19 de enero de 1895 se celebró una suntuosa velada en el salón de actos de la Escuela Normal de Profesores en honor de Joaquín García Icazbalceta, presidida por don Porfirio Díaz con los Secretarios de su Gabinete, sentándose Roa con los demás académicos a la izquierda del presidente Díaz. "Gutiérrez Otero leyó un discurso del finado escritor; Justo Sierra la bella oración oficial escrita por D. J. M. Vigil, y por último, el Ilmo. señor don Ignacio Montes de Oca recitó una magnífica elegía, y Casimiro del Collado leyó un canto hermosísimo como todos los stuyos." 29

Federico Gamboa, novelista y más tarde director de la Academia, nos da idea de lo que era dicha institución allá por el 13 de abril de 1896, cuando dice que alli "celébranse las sesiones... en el gabinete de trabajo del director actual de nuestra Biblioteca de San Agustín, a la vez director de la Academia Mexicana ... no asistieron hoy muchos académicos; el director; el secretario; el Prepósito de La Profesa, joven sacerdote muy lleno de virtud y ciencia, al decir de sus colegas y amigos; don José María Roa Bárcena, an- 
ciano respetable y leído ... y el licenciado Gutiérrez Otero, prestigiado en el foro." 30

La muerte de la patrona y protectora de Roa Bárcena, Susana Pesado de Teresa, hija del poeta Joaquín Pesado, cuya biografía trazó Roa con pluma magistral, acaeció el 4 de febrero de 1906. ${ }^{31}$ Fué su defunción una pérdida irreparable para don José María que perdía así "no sólo a la amiga de toda su vida, a la hija de su maestro, el poeta Pesado; sino también la sociedad de literatos y de amigos que en el despacho de la casa de la viuda de José de Teresa e hijas, hallaban siempre a Roa, y formaban con él constante academia. A la Mejicana dejaban de asistir sin escrúpulo ni sentimiento; pero al despacho de Roa Bárcena, jamás. Con la muerte de la ser̃ora se cerraron casa y despacho, y se disolvió el grupo académico, pues ya no era seguro encontrarlo, lejos de aquel centro de todos tan conoçido y de acceso tan fácil." 32

\section{LA ANTOlogia de poetas de mexico}

La disensión académica con don Marcelino Menéndez y Pelayo surge con respecto a una empresa encomendada por la Academia Mexicana al cuidado de Roa Bárcena y al de su buen amigo Casimiro del Collado. Con motivo de la celebración del cuarto centenario del descubrimiento de América, la Academia Española decidió honrar a sus hermanas americanas publicando una antología poética de autores exclusivamente hispanoamericanos. En julio de 1892 comisionó la docta corporación ibérica al ilustre crítico Menéndez y Pelayo para que formase la colección. Roa y Collado hicieron su selección que fué dividida en dos partes: poetas muertos y poetas vivos. Como era de esperarse, los bardos vivos ocupaban más espacio que los muertos. Gran desaire fué para la Academia Mexicana y para Roa Bárcena y Collado el no haber escogido el crítico santanderino sino muy contados poemas de los sometidos por la corporación mexicana, tomando en consideración únicamente los muertos. E1 mismo Menéndez y Pelayo nos dice que la Academia Mexicana, siguiendo la invitación que se extendió a todas las academias americanas "había llevado su exquisita cortesía hasta el punto de imprimir, para mayor comodidad de la nuestra, una Antología de: 
poetas de aquella República, en tirada de sólo seis ejemplares (según mis noticias). Y para que quede memoria de esta rareza bibliográfica, me parece oportuno dar aquí noticia del contenido de tan extraordinario libro, empezando por advertir que no tiene portada ni pie de imprenta (a lo menos por ahora), y que consta de 470 páginas, en 49, no foliadas, sino numeradas con lápiz." ${ }^{33}$ Luis González Obregón, en cambio, apuntó que "la Academia resolvió imprimir en corto número de ejemplares, tan corto que no llegó a diez, la Antología solicitada. La edición se hizo en la conocida tipografía de Ignacio Escalante, sin título ni compaginación, en un volumen 49 común ... Lo que sí lamentamos nosotros, es que por suma modestia no figuren poesías de los Sres. D. Casimiro del Collado y D. José María Roa Bárcena y no hay disculpa; pues así como ellos designaron las composiciones de sus colegas de la Academia, así éstos podían haber escogido las de los poetas compiladores... Por otra parte, la Academia debe enorgullecerse. Ha reunido por primera vez en un volumen las más preciadas joyas poéticas de nuestro antiguo y moderno parnaso. En una palabra, ha consumado una obra buena." 34 Veremos más tarde lo que dice el mismo Roa Bárcena sobre el número de ejemplares de esta antología.

Antes pasaremos a discutir el artículo "Antología de poetas de México" que se publicó, quizá por primera vez, en El Renacimiento, en su segunda época y en el número correspondiente al 4 de febrero de 1894, concluyéndose en el número del 11 del mismo mes y año. Más tarde se publicó este artículo de Roa Bárcena en las Memorias de la Academia Mexicana, tomo Iv, de 1895 (pp. 385405). Roa fechó su artículo el 22 de septiembre de 1893.

Anuncia don José María que en la convocatoria que mandó la Real Academia Española a las academias correspondientes americanas instándolas a que le mandasen las composiciones más notables de poetas muertos y vivos de América, se dijo que se destinarían a tales piezas dos tomos sin expresar tamaño. La Academia Mexicana designó entonces a Roa y a Collado para la elección de autores y versos y a Vigil para escribir la introducción del volumen que se formara.

Surgieron al formar la antología dos tendencias: "aspiraba una de ellas a que la colección fuera copiosa para dar idea lo más cabal posible de nuestros versificadores más notables, y a la otra a en- 
viar solamente lo que de indiscutible mérito se juzgara." 35 Al cabo se adoptó un medio entre tales extremos, dividiéndose la labor en dos secciones: muertos y vivos. Menciona Roa a continuación la lista de los poetas que se incluyeron, siguiendo el orden cronológico con los muertos y el alfabético con los vivos, y siendo mayor la lista de éstos. Quisiera haber podido ampliar el plan de la obra fara incluir a Bernardo de Valbuena, Alejandro Rivero, Federico Bello, Anselmo de la Portilla y algunos otros poetas españoles. Al no poder incluir traducciones, se impidió la reproducción de las obras de los padres Alegre y Ochoa, así como las de Couto, Castillo y Lanzas e Ignacio Mariscal.

En la introducción Vigil trazó clara y extensamente el desarro110 de la poesía mexicana, explicando sus modificaciones.

Para facilitar su tarea a la Real Academia Española y evitar erratas, la Mexicana hizo imprimir a costa de sus miembros "seis u ocho ejemplares de un tomo de cerca de 500 páginas, sin portada, de los cuales envió dos a Madrid en febrero y marzo de 1892 . Fueron recibidos sin demora, y creímos que los seis meses libres, de marzo a octubre, bastarían para incluir en la colección hispanoamericana lo remitido; tanto máś cuanto que se suplicó a aquella corporación que de los materiales puestos en su poder, escogiera lo conveniente a su objeto, y ni por un momento nos figuramos que en su totalidad lo prohijara." 36 A pesar del tono de reproche que se nota en estas palabras, Roa excusa a la Academia Española, ya que lo vasto del plan trazado impidió realizarle en la época fijada, y sólo había aparecido el primer tomo de la Antología de poetas hispanoamericanos de Menéndez y Pelayo cuando Roa Bárcena escribía su artículo en septiembre de 1893. No guarda don José María rencor a Menéndez y Pelayo, pues apunta que la poesía de México y Centro América llena dicho tomo, en que, "ante todo, brillan la magistral exposición y el juicio crítico de tan eminente humanista." 37

De los poetas muertos escogidos por los compiladores mexicanos, se incluyeron en la antología de la Academia Española a Sor Juana Inés de la Cruz, Navarrete, Quintana Roo, Ortega, Gorostiza, Rodríguez Galván, Pesado, Carpio, Arango y Escandón, Ramón I. Alcaraz, Francisco de P. Guzmán, Juan Valle, Rosas Moreno, Acuña y Flores. 
Añade Roa que, según la postdata del libro de Menéndez y Pelayo, fechada en enero de 1893, la Academia Española antes de las vacaciones de julio de 1892, dió a don Marcelino el encargo de formar la colección y escribir las necesarias introducciones, pero "la circunstancia de haberse él trasladado inmediatamente a Santander le impidió examinar los materiales que ya habían comenżado a remitir las academias correspondientes americanas; y en septiembre dió por terminados los trabajos relativos a México, Guatemala y Cuba, valiéndose exclusivamente de sus propios libros y de los de algún amigo suyo. Formada ya su colección respecto de los expresados países y redactado el prólogo, volvió el señor Menéndez y Pelayo a Madrid, y examinó entonces los datos recibidos de América; entre ellos el volumen enviado por la Academia Mexicana, del cual da sucinta noticia y tomó composiciones de don Ramón Isaac Alcaraz y de don Juan Valle. Insertó en la misma "Postdata" algún soneto de don José Sebastián Segura, a quien no habia incluído en su propia colección por suponerle vivo, e hizo mención honorífica del doctor Peredo, anotando que "ha dejado más fama como prosista y crítico de teatros que como poeta." 38

Arguye don José María que en la convocatoria, la Real Academia decía que incluiría a muertos y vivos, pero que este plan se modificó más tarde en el sentido de no contarse ya con los segundos; notando también que el nacimiento en el país de que se trata es el que determina entre otras cosas su entrada en la antología de ese país.

Después de leer la antología de Madrid, se confirma Roa en su idea de que la selección de poetas muertos que Collado y él hicieron, pecó por exigua, tanto en la selección de autores, como en la inserción de composiciones, admitiendo que la selección de poesías ha sido más feliz y atinada allende el mar que en México, lo cual nada tiene de extraño, "atendidas las dotes literarias de la persona que en Madrid se encargó de tal selección." 39

Muéstrase agradecido el compilador mexicano a la Real Academia por el puesto de honor que ha dado a México y el juicio que el editor de la antología ha formado de sus poetas, que "si bien se funda en cánones admitidos y consagrados por el Arte, deja trasparentar la benevolencia y. el cariño que a México y a los mexicanos en más de una ocasión ha mostrado el juez (y) decir esto a boca 
llena y dejarlo consignado en nuestros modestísimos anales literarios, constituye el principal objeto del presente artículo." 40

Pero a pesar de sus buenos propósitos, cede Roa a la debilidad de exponer sus ideas personales acerca de algunos puntos de la antología de Menéndez y Pelayo, "no en son de discordia ni con el presuntuoso fin de apelar de fallos que debemos respetar y acatar, sino con el honrado deseo de que se comprenda el espíritu que informó las modestísimas labores de nuestra comisión, y de proponer, en poquísimos casos, puntos de vista quizá más favorables o más adecuados a veces... en cuanto al carácter y las producciones de algunos de los escritores nuestros catalogados." 41.

Entiende el crítico mexicano que en la poesía lírica son rarísimos los ejemplos del buen éxito total o aun predominante en las. poesías de sus más distinguidos cultores; entiende también que en materia de originalidad, "nada hay nuevo después de la Biblia y de Homero, los cuales libro y hombre, contrayéndonos a la parte humana y temporal del primero, ya recogieron y acopiaron el acervo de ideas y conocimientos existente en sus épocas respectivas." 42

Por lo tanto mantiene don José María que en las antologías de poetas modernos no hay que vincular en la alta inspiración sostenida ni en la originalidad, el derecho de entrada. Hay que conformarse con "unas cuantas chispas de genio, unos cuantos rasgos de perfección relativa en la forma", "43 o se corre el riesgo de dejar en blanco las páginas destinadas a la obra de un poeta.

Poetas de primer orden le parecen al jalapeño Byron, Goethe, Schiller, Hugo, Manzoni, Leopardi, Quintana, Gallego y Núñez de Arce entre los modernos; atunque en México, según él, no hay tales y tenemos que conformarnos con Sor Juana, Navarrete y Pesado, a quienes, sin embargo, no considera inferiores ni a Bello, ni a Olmedo, ni menos a Heredia. Las cualidades de los mexicanos compensan e igualan, si no superan, el mérito de los sudamericanos, "por una composición de cada cual, composición a que ni siquiera se aproximan otras de las de cada uno de los tres poetas últimamente mencionados." 44

En la poesía "La agricultura de la zona tórrida" encuentra el poeta veracruzano poca originalidad, si no en su plan y condición generales, sí en sus detalles, luciendo reminiscencias y hasta pensamientos y frases y palabras de Virgilio, Horacio, Rioja y Quintana, 
pero "para los que no creemos, por regla general, en la originalidad y novedad de lo bueno moderno, constituye esto mérito antes que defecto; $y$, por otra parte, la pintura de los frutos y escenas de la América Meridional es, al par que bella, perfectísima y muy del autor." 45 Le parece a Roa demasiado extensa la silva, encontrándole repetición de ideas, somnolencias, desleimientos y descuidos, tono de sermón y prosaísmo en algunos versos.

En cuanto a la composición al Niágara de José María Heredia, confiesa Roa Bárcena que "nunca excitó mucho mi entusiasmo, salvo los versos del 26 al 54, en que valientemente se describe la catarata”, 46 juzgándola además desaliñada y defectuosa.

A propósito de Olmedo, deplora el mexicano que en la antología de Menéndez y Pelayo no se haya incluído la poesía épica de Manuel M. Flores, principalmente la consagrada a la victoria del 5 de mayo de 1862, que es la mejor de ese poeta, y "acaso de cuantas poesías patrióticas se han escrito en México (y) ... a pesar de su intercadente desaliño, de algunos defectos de elocución, de la debilidad relativa de su final y del atrevimiento y rareza de metáforas y frases; ... por su entonación vigorosa, lo sostenido de su inspiración patriótica, la sonoridad y rotundidad de muchos de sus versos, lo enérgico y feliz de no pocas de sus imágenes y la espontaneidad y la vida que en ella campean, si bien no podrá aparecer en la misma línea, no figurará en muy humilde lugar cuando la comparemos con la célebre composición de Olmedo," 47

La estimación que Roa profesaba a Fernando Calderón como uno de los padres del teatro mexicano fué responsable de la adopción y el envío a la Real Española de "E1 sueño del tirano" que, con razón, no fué aceptada por Menéndez y Pelayo en su antología. Impresiones y simpatías de los primeros años le impulsaron a in. cluir a Alpuche; pero no cree Roa Bárcena que por haber sido más filólogos que poetas Gómez de la Cortina y Peredo, y por haber muerto español el primero, que había nacido, vivido y escrito en México, se les deje de incluir en la colección de la Academia Española.

Don José María cree que por gongorista no incluyó don Marcelino al poeta del décimonono Agustín $F$. Cuenca. $Y$ de Acuña, prefiere el "Nocturno a Rosario" al "Ante un cadáver", que fué la poesía que se reprodujo en la antología de Madrid, y también está 
inconforme con la excltisión de Manuel Sánchez de Tagle, a pesar de que está de acuerdo en que se le excluya, si se le juzga por la oda remitida, que fué la "Oda a Iturbide." Reconoce en este poeta su desaliño y su prosaísmo, pero reconócele también su "bien entendida lectura de los poetas latinos y castellanos, y rasgos propios de ternura, verdadera inspiración y feliz ejecución." 48

Cuando pasa a discutir la obra de Manuel Carpio, observa el académico mexicano que "si se anotan sus despilfarros de color y de brillo, la nimiedad y redundancia de sus descripciones, y sus frases y giros de prosaísmo desesperante ¿̇ no será justo señalar también sus momentos felices, las partes de su factura en que se adelantó a la actual escuela realista en el buen sentido de la palabra, los pasajes suyos que llevan el sello épico?" 49 No hay que olvidar que el mismo Roa Bárcena ya había dictado su conferencia sobre Carpio en la Sociedad Literaria Sánchez Oropesa de Orizaba, la noche del 4 de abril de 1891 en la velada extraordinaria dedicada a celebrar el centenario del nacimiento de Carpio. ${ }^{50}$

Al hacer una comparación entre los méritos respectivos de Carpio y de Pesado como poetas, Roa Bárcena está de acuerdo con Menéndez y Pelayo en el fallo dado a favor de Pesado. También ya para estos tiempos había Roa escrito su magistral Biografía de don José Joaquín Pesado, publicada en edición muy roabarceniana de 100 ejemplares por Ignacio Escalante en 1878, y que tal vez había ya aparecido antes en las columnas de La Voz de México, aunque hasta la fecha no hemos podido verificar el dato. Roa Bárcena conoció personalmente a Carpio y a Pesado y estaba muy bien enterado del contenido de la obra de ambos poetas.

El crítico de Jalapa concluye su artículo explicando que "no es remoto que el campanario de la aldea haya de ser lo predominante y más perspicuo en el descolorido paisaje; y ... es muy posible que importe debilidad mayor que la de haberle bosquejado, la de no borrarle y suprimirle." 51

Como se ve, no habrá caído muy bien la antología de Menéndez y Pelayo a nuestro sexagenario Roa Bárcena y menos el desaire que le hizo aquel a quien tanto admiraba y respetaba. No era Roa hombre capaz de guardar rencor a nadie; su integridad y entereza no le permitían cegarse ante la verdad ni resentir una discrepancia tan notable en cuestiones de crítica, pero no cabe duda que en este caso 
sí le dolió bastante el incidente, viniendo como venía del que consideraba como uno de los mejores críticos que había producido la España de todos los tiempos. Es por eso que el 23 de septiembre de 1893 escribe su artículo "Antología de poetas de México", en que se atreve a expresar juicios contrarios y corregir otros de los de su idolo. Por supuesto, Roa Bárcena hace sus observaciones con la mesura, corrección y decoro que siempre caracterizaron sus escritos.

Para templar un poco el desagravio que sus dos académicos Roa y Collado habían sufrido por parte de la Rèal Academia Española, la Academia Mexicana publicó una segunda edición de la antología de poetas mexicanos que habían compilado aquéllos en 1892, y que, èn realidad, era la primera que se daba al público en el año de 1894. ${ }^{52}$ Esta segunda edición se publicó a expensas de la Academia Mexicana y parece haber sido sencillamente una reimpresión de la primera edición que se envió a la Academia Española y de la cual, como ya bemos visto antes, se hicieron tal ve $z$ unos seis $u$ ocho ejemplares según Roa Bárcena. Hasta la fecha no hemos podido desctubrir el paradero de los otros 4 ó 6 ejemplares que, sin duda, habrán quedado en México. La hija de Roa Bárcena, doña Concepción Roa y Villamil, no encontró en la biblioteca que le dejó su padre ningún ejemplar de dicha antología. No pudimos, sin embargo, cerciorarnos de este hecho personalmente, y es muy probable que haya habido algún ejemplar de esta obra entre los papeles que Roa dejó al morir. I a señorita Roa y Villamil ha fallecido ya y es difícil ahora comprobar estos datos.

Le ayudó en la compilación de la antología a Roa Bárcena su amigo de muchos años, el poeta español Casimiro del Collado. Yà en enero de 1869 había publicado Roa Bárcena unos apuntes sobre "Poesías de D. Casimiro del Collado" 53 y en 1894 le dedica su poesía "Los padres de la muerta" ".54 con motivo de la defunción de una hija de Collado.

En la advertencia de la antología se menciona el motivo por el cual se llevó a cabo esta segunda edición, pues "deseosa ahora la Academia Mexicana de que esos trabajos sean conocidos por lo que pueđa importar para nuestra historia literaria, acordó hacer esta segunda edición, reproducción exacta de la primera, siendo de advertir que conforme a la invitación referida, se incluyeron en la Antología composiciones de autores muertos y vivos, así mexicanos, como ex- 
traños que hubiesen residido y escrito en México." 55 Esta advertencia apenas deja entrever el motivo principal de la nueva edición: compensar los trabajos de Roa y Collado que en tan poco habían sido considerados por la Real Academia Española en su colección.

Acompaña a la antología la ya famosa "Reseña histórica de la poesía mexicana" escrita por el académico José María Vigil. Después vienen las selecciones de los poetas muertos entre los cuales figuran Francisco de Terrazas, González de Eslava, Sor Juana, Navarrete, Sánchez de Tagle, Quintana Roo, Gorostiza, Carpio, Ortega, Gómez de la Cortina, Pesado, Heredia, Alpuche, Calderón, Díaz, Ro-* dríguez Galván, Miguel J. Martínez, Segura, Ignacio Ramírez, Ramón Isaac Alcaraz, Arango y Escandón, Francisco de P. Guzmán, Peredo, Prieto de Landázuri, Juan Valle, Rosas Moreno, Flores, Acuña y Cuenca, varios de ellos académicos. Entre los poetas vivos encontramos a: Altamirano, Bustillos, Antonio Cisneros Cámara, Cuéllar, Delgado, Manuel y Salvador Díaz Mirón, Ricardo Domínguez, Adalberto A. Esteva, José María Esteva, Fernández Granados, Rafael Gómez, Ernesto González, Justo P. González, Manuel M. González, Gutiérrez Nájera, Híjar y Haro, Ipandro Acaico (el obispo Montes de Oca), Francisco López Carvajal, López Portillo, Vicente Daniel Llorente, Laura Méndez de Cuenca, Luis G. Ortiz, Othón, Pagaza, Porfirio Parra, Peón Contreras, Peón del Valle, Josefina Pérez de García Torres, Ignacio Pérez Salazar, Isabel Pesado, Pęza, Prieto, Puga y Acal, Ambrosio Ramírez, Riva Palacio, Justo Sierra, Sosa, Esther Tapia de Castellanos, Urbina, Valenzuela, Eduardo del Valle, Ramón Valle, Antonio Zaragoza, Rafael de Zayas Enríquez y Ovidio Zorrilla, ilustre lista en la cual figuran también varios prominentes académicos de número y correspondientes.

\section{MENENDEZ Y PELAYO $Y$ ROA BARCENA}

Ya desde unos años antes de la aparición de la antología de la Academia Española, Roa Bárcena había cruzado correspondencia con don Juan Valera y don Marcelino Menéndez y Pelayo. Valera en una ocasión escribió que era Roa Bárcena "de los hombres más eminentes y simpáticos de ese país. Conozco sus poesías líricas que él mismo me ha enviado; pero sólo sé por fama, y tengo gran deseo 
de ver sus leyendas históricas de antes de la conquista española y sus eruditos trabajos en prosa como historiador del Anáhuac. E1 señor Roa Bárcena es también novelista; $\mathrm{y}$ dan sin duda brillante prueba de su mérito en esta clase de escritos los V arios cuentos, reunidos en un precioso volumen ... Noche al raso es lindísima colección de anécdotas y cuadros de costumbres, donde el ingenio, el talento y la habilidad para narrar están realzados por la naturalidad del estilo y por la gracia y el primor de un lenguaje castizo y puro, sin la menor afectación de arcaísmo. En el terrible cuento Lanchitas, la fantasía del autor y su arte y buena traza prestan apariencias de . verosimilitud y hasta de realidad al prodigio más espantoso." 56 Estos Varios cuentos de que habla Valera son los que se publicaron en 1882 en edición de 60 ejemplares y en 1883 en edición de El Nacional y que contienen "El rey y el bufón", "Noche al raso" y "Lanchitas".

La hija de Roa Bárcena, doña Concepción, nos aseguró que tenía su padre la costumbre de destruir todas las cartas que recibía en lugar de guardarlas. Gran lástima es que don José María no haya guardado esas epístolas que sin duda recibió de literatos y hombres prominentes de México y de España. Afortunadamente, y, como él mismo lo confiesa, en un momento de debilidad, llegó a publicar varias cartas que recibió de Menéndez y Pelayo en su último tomo de poesías de 1895. Muestran estas cartas la gran admiración que Roa tenía por el académico español por la religiosidad con que siguió al pie de la letra, en la mayoría de los casos, los consejos del ilustre crítico. Pasaremos a discutir más en detalle estas cartas, principalmente en lo que se refieren a las traducciones de Horacio y de Shakespeare.

Parece que Roa Bárcena empezó a comprender la necesidad de conocer el latín y leer a los clásicos de ese idioma en el original. A este fin se dedicó a aprender el latín bajo la tutela de Rafael Angel de la Peña, gramático y académico. Sin embargo, antes de dedicarse en regla a tal aprendizaje, escribió en el año de 1865, en pleno imperio de Maximiliano, unas imitaciones de Horacio, de las cuales se ha publicado en sus colecciones de poesías únicamente la que llamó "La nave de Virgilio", que es la oda tercera del libro primero del protegido de Mecenas. El humanista mexicano, doctor Gabriel Méndez Plancarte, la encuentra "atildada como todo lo suyo, pero demasiado parafrástica", ${ }^{57}$ confesando que las estrofas de Roa son 
bellas en sí pero aun así están muy lejanas de la fuerte concisión de Horacio.

Ese mismo año de 1865 tradujo o imitó Roa otra oda de Horacio que llamó "El lujo", que no es otra que la oda xv del libro II. Según el mismo Menéndez y Pelayo, únicamente Francisco de Medrano y Rafael Pombo la han vertido al castellano. ${ }^{58}$ Según Méndez Plancarte, en su obra Horacio en México, no ha habido traductores mexicanos de esta oda. Es, por 10 tanto, Roa Bárcena el primero en México de lớs traductores, o por lo menos, imitadores conocidos de dicha oda. Esta oda quedó sepultada en las columnas de La Socie$d a d,{ }^{59}$ periódico de la época de Maximiliano que dirigía Roa Bárcena, y no apareció más en ninguno de sus libros. Por juzgarla inédita, pues, la insertamos a continuación, dejando a los inteligentes conocedores de estos asuntos el criticarla. Esta versión está tomada de uno de los borradores de Roa Bárcena que nos facilitó su hija para examinarlos y que hemos depositado en "microfilm" en la Biblioteca de la Universidad de Illinois. Son tres los borradores que hemos llamado arbitrariamente cuadernos I, II y IIr y de cuya descripción nos ocuparemos en otra ocasión. Tomamos la versión de "El lujo" del cuaderno I, por no hallarse completa en el cuaderno II, faltándole los nueve últimos versos:

\section{El lujo}

Del labrador al sulco espacio breve

Dejan ya en la campiña

Estanques y palacios, y se mueve

Arbol sin fruto en el lugar que debe

Al olmo protector de la útil viña.

Mirtos y arbustos de olorosa goma

$\mathrm{Y}$ blancos azahares

Cubren los campos fértiles de Roma

Do a posesor más cuerdo, si no aroma,

Daban riqueza ayer sus olivares.

Del sol para evitar el rayo ardiente

Hay ya bosques enteros

Del laurel que no ciñe nuestra frente.

Lujo y molicie tal la edad presente

Halla en Catón y Rómulo severos?

Bajo aquestos varones, al Estado,

Cual la nieve en aludes,

Vino el rico tesoro ambicionado, 
$Y$ el ciudadano en el hogar privado Guardó el sólido bien de sus virtudes.

La ley mandóle conservar la estancia Los que dellas ejemplos

De sus padres tomó desde la infancia, Y del mármol y el oro la arrogancia Destinó a las ciudades y los templos.

Todavía es imitación y no traducción, la poesía "A una fuente" que compuso Roa Bárcena en 1874 e incluyó en sus Nuevas poesías de 1875. Aún no se había dedicado de lleno don José María al estudio de la lengua del Lacio, y por eso podemos decir con el obispo Montes de Oca: "Cómo pudo llegar Roa, sin comprender a fondo el original, a la altura en que se colocó en su noble intento, es un verdadero misterio." " ${ }^{\circ}$ Al compararla con "La nave de Virgilio", Méndez Plancarte la considera "menos parafrástica, pero también poco horaciana." ${ }^{1} 1$ En una carta fechada en Santander el 11 de enero de 1890 , Menéndez y Pelayo, al acusar recibo de las Leyendas mexicanas y Nuevas poesias, dice que en este último libro ha encontrado "dos versiones de Horacio que omití en mi libro sobre aquel poeta, y añadiré con otras nuevas si 1lego a hacer algún día nueva edición de aquel ensayo." 62 ¡Lástima grande es que Menéndez y Pelayo no haya sido más explícito en este caso!

Ya son obras más maduras que muestran mayor conocimiento del idioma y más apego al original las traducciones que hizo Roa de Horacio el año de 1890. Con razón dice el ya mencionado crítico mexicano Méndez Plancarte: "veinte años después, dueño ya del instrumento lingüístico que le permitía penetrar las bellezas de la forma horaciana, y aprovechando - con modestia ejemplar en hombre de sus ar̃os y de su mérito- las observaciones que en carta privada le comunicó Menéndez y Pelayo, publicó Roa Bárcena las otras dos traducciones mencionadas." "33 Se refiere aquí el antiguo editor de Abside a las cartas que incluyó Roa en el prólogo de "E1 autor al lector" de sus Uliminas poesías líricas de 1895, en las páginas 6 a 9. Como el mismo Roa Bárcena apunta en el prólogo, "agradecido a encomios y lastimado de azotes que ningún cultivador del Arte, por muy poco que valga, deja de recibir, caigo en la debilidad de publicar en seguida tres cartas del insigne humanista don Marcelino Menéndez y Pelayo, con juicios rápidos y confidenciales de versos míos, 
antiguos y modernos. Comprendo que en tales juicios, aủn más que la pericia del Maestro, resaltan la benevolencia y el cariño con que me favorece; pero también se comprenderá fácilmente lo que una y otro me refrigeran y confortan." 64 Hay que tener en cuenta que Roa Bárcena escribía esto de Menéndez y Pelayo el 30 de junio de 1895, algún tiempo después de haber ocurrido la controversia con motivo de la antología de poetas mexicanos. Palabras son éstas que demuestran que Roa no era rencoroso y que su admiración por don Marcelino seguía en pie.

La primera carta es de Madrid con fecha 20 de abril de 1889 , pero las otras clos son de Santander, del 11 de enero de 1890 una, y del 13 de septiembre de 1890, la otra. Es en la carta última que, al acusarle recibo de las versiones de "Romeo y Julieta" y de las odas horacianas "Maecenas atavis" y "Quis multa gracilis", el erudito español declara que "las tres son felices muestras del arte y habilidad con que sabe Ud. acomodar a nuestra lengua los conceptos de los poetas extranjeros." 65 Más adelante, en la misma misiva, pasa Menéndez y Pelayo a sugerir las correcciones de que habla Méndez Plancarte en su Horacio en México. Dice el de Santander: "En la primera traducción de Horacio (la oda a Mecenas), noto que el atavis regibus dice algo más que regia estirpe, puesto que indica la antigüedad de esos reyes. En la mudable turba hay que expresar que es turba de Quirites, como dice el texto. Attalicis conditionibus son las riquezas de Atalo prometidas más bien que entrevistas. El ad aquae lene caput sacrae comprendo que es difícil de traducir conservando la exquisita poesía del original; pero a lo menos hay que hacer sentir que se trata del agua de una fuente sagrada; y en esto han pecado de omisión casi todos los traductores. Con poner sagrado en vez de sonoro los aventajará usted en fidelidad y poesía; pero habría que retocar el verso anterior para que no resulte consonante. Horacio nombra dos instrumentos de música guerrera, el lituo y la tuba: convendrá meter entrambos si se puede. En olvido de la gentil esposa es algo anfibiológico. ¿Es el cazador el que se olvida de la esposa, como dice el texto (conjugis immemor); o es la esposa la que se olvida del cazador? Poniendo olvidado se salva la dificultad." 66

Veamos ahora si siguió al pie de la letra el traductor mexicano las instrucciones del crítico español. 
E1 primer verso de esta primera oda del primer libro de Horacio, según el cuaderno III del vate jalapeño dice:

Oh Mecenas, varón de regia estirpe!

En el tomo de poesías de 1895 aparece ya el verso:

iOh Mecenas, de antigua regia estirpe! 67

Donde en su cuaderno decía:

De la mudable turba hasta la cima

en las poesías coleccionadas dijo:

De la mudable turba de Quirites. ${ }^{68}$

Más tarde, en el cuaderno se lee:

$\mathrm{Ni}$ las riquezas de Atalo, entrevistas,

y en el libro impreso:

De Atalo las riquezas prometidas, ${ }^{69}$

En tanto que en el manuscrito se lee:

Bajo madroño fresco, reclinado

o allí do manantial sagrado brota.

en el tomo de versos dice:

Bajo el madroño fresco, o en la blanda margen de manantial sacro tendido. ${ }^{70}$

En su colección poética dijo:

A cuantos place el campamento, el rudo Son del clarín y trompa, la impía guerra Que detestan las madres! Olvidando A la gentil esposa, a la intemperie Quédase el cazador...71

cuando en su borrador había dicho:

A cuantos place el campamento, el rudo Son del clarín y asoladora guerra 
Que detestan las madres! En olvido De la gentil esposa, a la intemperie Quédase el cazador...

Muestran estas correcciones y enmendaturas la alta opinión que tenía Roa Bárcena del criterio literario de Menéndez y Pelayo. Otro menos modesto que el veracruzano hubiera desdeñado el consejo del académico santanderino, $\mathrm{y}$ aun se habría enfadado sintiéndose ofendido en su dignidad literaria al ver que otro ponía en género de duda sus versos. Roa, con su proverbial modestia, no sólo acepta los juicios y consejos del español, sino que agradece humildemente la ayuda que se le presta.

Esta oda a Mecenas ha tenido varios traductores famosos, entre ellos fray Luis de León, Pesado y Sánchez de Tagle. El doctor Gabriel Méndez Plancarte dice de la traducción de Roa que "no es mejor que la de Pesado porque ésta es 'verdaderamente insuperable' (palabras de Menéndez y Pelayo); pero sus nobles endecasílabos libres y su exquisita fidelidad me hacen preferirla a casi todas las demás versiones de dicha oda que existen en castellano." 72

La otra oda que tradujo Roa Bárcena en 1890 es la quinta del libro primero, que llamó "A Pirra." En la misma carta de 13 de septiembre de 1890, Menéndez y Pelayo escribió a Roa Bárcena: "En la oda a Pirra, sin mancha por munditiis no me gusta. En primer lugar, no se sabe de qué mancha se trata; y, además, la palabra latina quiere decir algo más que limpieza: designa cierto género de aseo elegante y exquisito. El intentata no sé yo si está traducido: literalmente es no experimentada, no conocida por experiencia. Todo lo demás de estas traducciones me gusta muchísimo, y por la misma nimiedad de los reparos comprenderá Ud. el interés con que las he leído." 73 bió el

Siguiendo los consejos de don Marcelino, Roa Bárcena cam-

Sin mancha te le muestras,

que decía en el tercero de sus cuadernos, por

Limpia y pulcra te muestras, ${ }^{74}$ 
en su tomo de poesias del 95. No podemos comparar el cambio que hubo en los versos que dicen en las Ulimas poesias líricas:

¡ Míseros los que ofuscas

Sin que por experiencia te conozcan! 75

porque en sus cuadernos no se encuentra completa la oda a Pirra y se halla trunca a principios de la estrofa.

Son muchos los que han traducido al castellano esta oda, contándose entre ellos a fray Luis de León, el Brocense, Vicente Espinel, Lupercio Leonardo de Argensola, Pesado, Segura y el mismo Menéndez y Pelayo. ${ }^{76}$ También Miguel Antonio Caro hizo una traducción de esta oda entre los sudamericanos y Joaquín Casasús entre los mexicanos. $77 \mathrm{E} 1$ humanista Méndez Plancarte dice que la traducción de Roa Bárcena "encuentra también la temible - y victoriosa - competencia de Pesado. Gocemos, con todo, su no vulgar delicadeza." 78

Vemos, pues, que es ya sesentón el poeta cuando se dedica al estudio de los clásicos latinos, y "el insuperable traductor del 'Mazep- pa' de Byron el tempestuoso, sentía 1legar hasta su quieto retiro la perenne frescura de la serenidad horaciana; y su operosa vejez, al conjuro de la Musa antigua, reflorecía en brotes primaverales." 79

Allá por el año de 1889, la compañía dramática italiana de Giovanni Emmanuel puso en escena el 12 de febrero el "Hamlete" de Shakespeare que era el mejor que se había visto en México. Más tarde, esa misma compañía representó "Romeo y Julieta." so Es posible que Roa Bárcena haya asistido a estas representaciones ya que era muy afecto al teatro, y de allí haya concebido la idea de traducir trozos de estas dos obras dramáticas. En el número del domingo 22 de mayo de 1859 de La Sociedad aparece el parte oficial del gobierno de Miramón, nombrando una junta inspectora de teatros, de la cual es presidente Ignacio Aguilar y Marocho, secretario Francisco González Bocanegra, figurando José María Roa Bárcena como uno de sus vocales propietarios. ${ }^{81}$ No tenemos noticias de cuándo dejó de funcionar esta junta, aunque es casi seguro que se haya disuelto con la entrada de Juárez a la ciudad de México en 1861.

Es lástima que Roa no haya traducido más fragmentos de estas obras o de otras obras del poeta inglés, pues parece haber penetrádose bien del espíritu del genio del Avon. Es casi seguro que fué en 
la Revista Nacional de Letras y Ciencias donde publicó Roa Bárcena por primera vez sus fragmentos de "Romeo y Julieta" y de "Hamlet" en el año de 1889. ${ }^{82}$ Más tarde se reprodujeron estas traducciones en la famosa Revista $A z u l{ }^{83}$ y en su última colección de poesías líricas. ${ }^{84}$

Al referirse a la versión que hizo Roa Bárcena de "Romeo y Julieta", Menéndez y Pelayo en su carta de septiembre de 1890, dijo que no le parecía "completamente traducido el verso

That pierc'd the fearful hollow of thine ear,

que es muy shakesperiano, pero para nuestro gusto algo extraño. Me parece un poco débil la versión de este otro verso cuyo movimiento quisiera yo que se conservase en castellano con la misma rapidez:

Yon light is not day light, I know it, I.

Quisiera también que se hubiera conservado el pale reflex of Cynthia's brow, que me parece más poético que el fulgor de la luna a secas. La amorosa expresión $m y$ soul falta también. Por último echo de menos la repetición more light and light que tiene más fuerza que la luz se aumenta." ${ }^{85}$

A pesar de que Roa Bárcena dijo en el prólogo de su colección poética de 1895, Ultimas poesías líricas, que "por razón de impotencia, anticipadamente disculpada en las observaciones mismas del señor Menéndez y Pelayo", " ${ }^{86}$ no podía hacer uso de sus advertencias, a última hora lo intentó, como él mismo lo confiesa: "No obstante lo dicho en la introducción del presente libro, a última hora se ha procurado utilizar algunas de las advertencias del Sr. Menéndez y Pelayo acerca de estas versiones." ${ }^{87}$ Hay que recordar que Roa confesaba haberse aprovechado de los consejos del académico español después de haber publicado su crítica de la antología de Menéndez y Pelayo. El artículo de Roa en El Renacimiento es de febrero de 1894 y el prólogo de sus Ultimas poesias líricas tiene fecha de junio 30 de 1895.

Está tomado el fragmento de "Romeo y Julieta" del hermosísimo diálogo de los dos amantes en el balcón, en la escena $\mathrm{v}$ del acto III. Dice la Julieta de Shakespeare: 
Will thou be gone? it is not yet near day: It was the nightingale, and not the lark, That pierc'd the fearful hollow of thine ear; Nightly she sings on your pomegranate tree; Believe me, love, it was the nightingale. 88

La Julieta de Roa Bárcena ruega :

¡Cómo! ¿Ya quieres irte? Aún tarda el día. Fué el ruiseñor; no fué, no fué la alondra Quien alarmó tu receloso oído:

Todas las noches en aquel granado Su canto ensaya: él era ioh dueño amado! Crédito dame: el ruiseñor ha sido. 89

Más tarde la Julieta inglesa dice:

Yon light is not daylight, I know it, $I$ :

y la Julieta mexicana:

Sé bien que matutina luz no es ésa: 90

Estas son las únicas correcciones que intentó hacer don José María siguiendo los consejos de don Marcelino. Las demás correcciones que sugirió el crítico santanderino no se llevaron a cabo.

El fragmento de "Hamlet" está tomado de las escenas I, II, IV y $\mathrm{v}$ del primer acto, y está dedicada la versión a Menéndez y Pelayo. En la carta de enero 11 de 1890, Menénđez y Pélayo aseguró a Roa que "grande honra he recibido con la dedicatoria de las escenas del primer acto de "Hamlet" que Ud tan vigorosamente ha traducido, conservando todo el sabor de la misteriosa y terrible poesía del sublime original. Sólo dos o tres cosas insignificantes he notado, que quizá pueda Ud. retocar cuando reimprima este notable fragmento. Hay algo suyo por $A$ piece of him, no me gusta, aunque comprendo que la traducción literal, un pedazo de él, resulta prosaica en castellano. No encuentro en la traducción el Thou art a scholar, que en boca de soldados es muy característico. Pero todo esto son pequeñeces que nada quitan al mérito insigne de este ensayo, uno de los más afortunados que he visto en materia tan difícil!" 91 
Siguió Roa Bárcena con el "hay algo suyo" al que objetaba Menéndez y Pelayo; pero cuando Marcelo dice a Horacio, al aparecerse el espectro del padre de Hamlet:

Thou art a scholar; speak to it, Horatio.

el Marcelo mexicano dice:

Háblale, Horacio,

Ya que estudiante has sido. ${ }^{22}$

Ya en su carta del 20 de abril de 1889, Menéndez y Pelayo había alabado la traducción que había hecho Roa Bárcena del "Mazeppa" de Byron, diciendo que le parecía "un insuperable y bizarrísimo alarde de vencer dificultades métricas, siguiendo paso a paso sin descaecimiento ni fatiga la marcha caprichosa y vagabunda del texto original. Pocas veces se ha visto Byron en castellano tan bien interpretado, y quizá ninguna mejor." 93

Acertadísimo como casi todos los suyos nos parece el juicio de Menéndez y Pelayo acerca de las traducciones inglesas de Roa Bárcena. Se apega mucho al original, conservando su espíritu sin perder la elegancia que caracteriza casi todas sus traducciones. Muestran estas traducciones de Shakespeare que, a pesar de la controversia o disensión que había existido con motivo del desaire de la antología, Roa Bárcena todavía seguía los consejos de Menéndez y Pelayo en materia literaria aun cuando ya se había atrevido a poner en género de duda su juicio crítico en cuanto a la poesía mexicana.

Roa Bárcena, como crítico, poseía esa facultad de percibir la belleza y la practicaba en sus obras literarias; no le faltaba el estudio constante de la realidad y de los buenos modelos. Tenía buen gusto, gusto clásico pero también ecléctico que le permitía admirar las bellezas que encontraba en el romanticismo. Faltábale, sin embargo, ese calor, esa energía, esa pasión que algunos creen necesarios para que la crítica sea una producción literaria. Nunca pretendió ser crítico Roa; siempre expuso sus opiniones personales pero nunca trató de imponerlas al público, a su poco público. Si se metió a crítico en ocasiones, fué por defender sus principios literarios o religiosos, por tratar de presentar modelos de buen gusto a su generación para hacerla despertar e intentar que los emulase, y para poner más alto 
el nombre de su país que veía menoscabado al desairarse las obras de sus literatos.

No hubo brío, no hubo calor, no hubo pasión, no hubo odio destructor en la crítica de José María Roa Bárcena. Sí hubo raciocinio, templanza, labor constructiva pero con tal elemento de moderación y mesura, aunque concienzudamente estudiado y expuesto, que su crítica "per se" ha pasado inadvertida en muchos casos.

\author{
Renato Rosaldo, \\ Universidad de Winsconsin, \\ Madison, Wisconsin, EE. UU.
}

\title{
$\mathrm{N} O \mathrm{~T} A \mathrm{~S}$
}

i Colección de leyes, decretos y reglamentos que interinamente forman el sistema politico, administrativo y judicial del Imperio, tomo viII, México, Imprenta de Andrade y Escalante, 1865-1866, p. 15.

\section{Ibid.}

3 Victoriano Agüeros, Obras literarias, I, Artículos sueltos, México, Imp. de V. Agüeros, Editor, 1897. (Biblioteca de Autores Mexicanos, 8), pp. 387-388.

4 Annita Melville Ker, A survey of Mexican scientific periodicals to which are appended some notes on Mexican historical periodicals. Publication of the Harvey Bassler Foundation, 1931, p. 10.

\section{Ibid.}

6 Ibid.

7 Memorias de la Academia Mexicana Correspondiente de la Española, tomo séptimo, México, s. p. i., 1945, p. 377.

8 Ker, Op. cit., p. 12.

9 Memorias de la Academia Mexicana Correspondiente de la Española, tomo primero, México, Imprenta de Francisco Díaz de León, 1876, pp. 89204. La Imprenta de Ignacio Escalante publica también estos Datos en forma de libro este mismo año de 1876.

10 Ibid., tomo segundo, 1880, pp. 93-95.

11 Ibid., tomo tercero, 1886 , pp. 302-304. 
12 Ibrid., pp. 407-421.

13 Ibid., tomo cuarto, 1895 , pp. 343-344.

14 Ibid., pp. 385-405.

15 Ibid., tomo sexto, 1910, pp. 104-128.

16 Ibid., pp. 131-132.

17 Ibid., pp. 263-287.

18 Ibid., tomo primero, p. 20.

19 Ibid.

20 José María Roa Bárcena, Obras poéticas, tomo I, edición completa de 200 ejemplares numerados, México, Imprenta de Ignacio E'scalante, 1913, pp. 119-120. (Según la señorita Concepción Roa y Villamil, el tomo Ir no se publicó a pesar de haberse comprado el papel, por la situación azarosa por la cual pasaba el país y por la pérdida de dicho papel.)

21 Ibid., p. 112.

22 Ibid., p. 113.

23 Francisco Pimentel, Historia crítica de la literatura $y$ de las ciencias en México. México, Lib. de la Enseñanza, 1885, pp. 696-697.

24 Rafael Angel de la Peña, Obras. México, Imp. de V. Agüeros, editor, 1900 , p. 410.

25 Memorias de la Academia Mexicana, tomo tercero, p. 6.

26 Felipe Teixidor, Cartas de Joaquín García Icazbalceta. México, Ediciones Porrúa, 1937, p. 173.

27 Ibid., p. 263.

28 Memorias de la Academia Mexicana, tomo cuarto, p. 14.

29 Enrique Olavarría y Ferrari, Reseña histórica del teatro en México. $2^{a}$ edición, tomo IV, México, 1895, p. 510.

30 Federico Gamboa, Mi diario, la serie, 1, Guadalajara, Imprenta de "La Gaceta de Guadalajara", 1907, p. 263.

31 Roa Bárcena, Obras poéticas, I, p. 167.

32 Ibid.

33 Marcelino Menéndez y Pelayo, Antologia de poetas hispano-americanos. Publicada por la Real Academia Española, tomo I. México y América Central. Madrid, Est. Tipogr. "Sucesores de Rivadeneyra", 1893, pp. 385-386. 


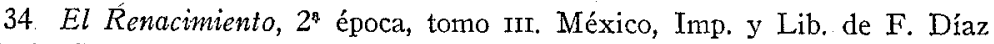
de León Sucesores, 1894, pp. 358-360.

35 Memorias de la Academia Mexicana, tomo cuarto, pp. 385-386.

36 Ibid., p. 388.

37 Ibid.

38 Ibid., pp. 389-390.

39 Ibid., p. 391.

40 Ibid., p. 392.

41 Ibid., pp. 392-393.

42 Ibid., p. 393.

43 Ibid., pp. 393-394.

44 Ibid., p. 395.

45 Ibid.

46 Ibid., p. 396.

47 Ibid., pp. 397-398.

48 Ibid., p. 403.

49 Ibid.

50 Publicada en Memorias de la Academia Mexicana, tomo tercero, pp. 407-421 y en Roa Bárcena, Biografias, tomo rv de las Obras. México, Imp. de V. Agüeros, Editor. (Biblioteca de Autores Mexicanos, 41.)

51 Memorias de la Academia Mexicana, tomo cuarto, p. 405.

52 Antología de poetas mexicanos. Publicada por la Academia Mexicana correspondiente de la Real Española, (editada por Roa Bárcena y Collado, aunque sus nombres no aparecen en la portada), $2^{a}$ edición. México, Oficina Tip. de la Secretaría de Fómento, 1894.

53 El Renacimiento. México, Imprenta de F. Díaz. de León y S. White, 1869 , I, pp. $24-29$.

54 Ultimas poesias líricas. Apéndice hasta mediados de 1895, edición de 150 ejemplares. México, Imprenta de Ignacio Escalante, pp. 98-99. También en las Memorias de la Academia Mexicana, v. nota 16.

55 Antología de poetas mexicanos, $2^{B}$ edición, pp. V-vI.

56 Juan Valera, Nuevas cartas americanas. Madrid, Librería de Fernando Fé, 1890 , pp. 81-82. 
57 Gabriel Méndez Plancarte, Horacio en México, ediciones de la Universidad Nacional, 1937, pp. 112-113.

58 Marcelino Menéndez y Pelayo, Horacio en España, tomo I, $2^{\natural}$ edición refundida. Madrid, Imprenta de A. Pérez Dubrull, 1885. (Colección de E'scritores Castellanos, 27), pp. 338-339.

59 La Sociedad. México, tercera época, tomo IV, núm. 669, abril 22 de 1865 , p. 2 ,

60 Roa Bárcena, Obras poéticas, I, p. 136.

61 Gabriel Méndez Plancarte, Op. cit., p. 114.

62 Roa Bárcena, Ultimas poesías líricas, 1895, p. 8.

63 Méndez Plancarte, Op. cit., p. 114.

64 Roa Bárcena, Ultimas poesías líricas, 1895, pp. 5-6.

65 Ibid., p. 8.

66 Ibid., p. 9.

67 Ibid., p. 30.

68 Ibid.

69 Ibid.

70 Ibid.

71 Ibid., p. 31.

72 Méndez Plancarte, $O p$. cit., p. 115.

73 Roa Bárcena, Ultimas poesías liricas, 1895, p. 9.

74 Ibid., p. 31.

75 Ibid., p. 32.

76 Menéndez y Pelayo, Horacio en España, I, p. 339.

77 Méndez Plancarte, Op. cit., p. 316.

78 Ibid., p. 116.

79. Ibid., p. 117.

80 Olavartía y Ferrari, Op. cit., Iv, p. 83.

81 La Sociedad. Segunda época, tomo III, núm. 505, mayo 22 de 1859, pp. 2-3. 
82 Revista Nacional de Letras y Ciencias. México, Imp. de la Secretaría de Fomento, tomo II, 1889, pp. 147-148 (Romeo y Julieta) y pp. 426-442 (Hamlet).

83 Revista Azul. El domingo de "El Partido Liberal". México, Tip. de "El Partido Liberal", tomo I, 1894, p. 339 (Romeo y Julieta).

84 Roa Bárcena, Ultimas poesías líricas, 1895, pp. 54-56 (Romeo y Julieta), y pp. 56-73 (Hamlet).

85 Ibid., pp. 8-9.

86 Ibid., p. 10.

87 Ibid., p. 54.

88 William Shakespeare, Complete Works. New York, Cleveland, World Syndicate Company, Inc., 1927, p. 911.

89 Roa Bárcena, Ultimas poesias liricas, 1895, p. 54.

90 Ibid., p. 54.

91 Ibid., p. 8.

92 Ibid., p. 58.

93 Ibid., p. 6. Véase también nuestro artículo sobre "Un traductor mexicano de Byron" que apareció en la Revista Iberoamericana, vol. xvII, núm. 34, enero de 1952, pp. 243-252. 